\title{
Chemical Modelling with CHASER and WRF/Chem in Japan
}

\author{
M. Takigawa ${ }^{1}$, M. Niwano ${ }^{1}$, H. Akimoto ${ }^{1}$, and M. Takahashi ${ }^{1,2}$ \\ [1] \{Frontier Research Center for Global Change, Japan Agency for Marine-Earth Science and \\ Technology, Yokohama, Kanagawa, Japan\} \\ [2] \{Center for Climate System Research, University of Tokyo, Kashiwa, Chiba, Japan\} \\ Correspondence to: M. Takigawa (takigawa@jamstec.go.jp)
}

\begin{abstract}
Here we would like to briefly introduce our modeling studies with WRF/Chem and CHASER. CHASER (chemical atmospheric general circulation model for study of atmospheric environment and radiative forcing) is a global chemical transport model. (cf. Sudo et al 2002a, 2002b, Takigawa 2005). The gaseous and aerosol chemistry module is implimented in the CHASER model in an on-line treatment. CHASER is based on CCSR/FRCGC/NIES AGCM 5.7b, and the meteorology and radiation can be calculated in CHASER itself. The radiative feedback through the distribution of chemical species is taken into account in CHASER. Daily forecasts have been available on a web page since 1 January 2002. This forecasting system was developped for the use of daily flight planning for the PEACE-A (January 2002) and PEACE-B (April-May 2002). I will show you some results by using this global chemical weather forecasting system. We have been also developping a regional-scale chemical weather forecasting system based on WRF/Chem. The lateral boundary for the chemical species is taken from the 3-hourly output of CHASER. The model-calculated surface ozone by using this model system was compared with the ground-based observations.
\end{abstract}

\section{Introduction}

Recently, chemical transport models (CTMs) have enhanced flight planning by providing direct information on the expected state of important three-dimensional atmospheric chemical structures on timescales of hours to days, i.e., the "chemical weather". The first chemical weather forecasting was during ASHORE (Airborne Southern Hemisphere Ozone 
Experiment) and SESAME (Second European Stratospheric Arctic and Middle-Latitude Experiment) in 1994 and 1995 (Lee et al., 1997). The use of chemical weather forecasts for field campaigns is expanding rapidly. Global chemical weather forecasts from MATCHMPIC (Model of Atmospheric Transport and Chemistry - Max-Planck-Institute for Chemistry version) were used during INDOEX (Indian Ocean Experiment) in 1999 and MINOS (the Mediterranean Intensive Oxidants Study) and CONTRACE (Convective Transport of Trace Gases into the Upper Troposphere over Europe) in 2001 (Lawrence et al., 2003). In contrast to regional chemical weather forecasts, global chemical weather forecasts can predict intercontinental transport. For example, Lawrence et al. (2003) estimated the frequency of intercontinental pollution plumes from North America and Asia to Europe. Chemical weather forecast systems using regional scale models have a horizontal resolution advantage over global models. The Chemical Weather Forecasting System (CFORS) was used during TRACE-P and the ACE-Asia campaign in 2001 (Uno et al., 2003). Uno et al. (2003) showed that changes in synoptic-scale weather greatly influence continental-scale pollution transport in the spring over East Asia.

This paper describes a newly developed global chemical weather forecasting system based on CHASER (chemical atmospheric general circulation model for study of atmospheric environment and radiative forcing) that can be used to support atmospheric chemistry field campaigns. The model includes radiative and dynamical processes and comprehensive chemical schemes for the troposphere and lower stratosphere. This paper assesses the quality and estimates the value of chemical weather forecasts from the model that was used in flight campaigns.

\section{Global Chemical Weather Forecasting System}

The chemical weather forecast system includes the coupled tropospheric chemistry climate model CHASER, which is described and evaluated in Sudo et al. (2002a, b). Physical and dynamical processes are simulated following the Center for Climate System Research/National Institute for Environmental Study/Frontier Research Center for Global Change (CCSR/NIES/FRCGC) atmospheric GCM (Nakajima et al., 1995; Numaguti, 1993; Numaguti et al., 1995). The CHASER model in this study is based on CCSR/NIES/FRCGC AGCM version 5.7b. Advective transport is simulated with a $4 t h$ order flux-form advection scheme using a monotonic Piecewise Parabolic Method (PPM) (Colella and Woodward, 
1984) and a flux-form semi-Lagrangian scheme (Lin and Rood, 1996). Subgrid-scale vertical fluxes of heat, moisture, and tracers are approximated using a non-local turbulence closure scheme based on Holslag and Boville (1993) used in conjunction with the level 2 scheme of Mellor and Yamada (1974). The cumulus parameterization scheme is based on Arakawa and Schubert (1974) with several simplifications described in Numaguti et al. (1997). The closure assumption is changed from the diagnostic closure used in Numaguti et al. (1997) to a prognostic closure based on Pan and Randall (1998), in which cloud base mass flux is treated as a prognostic variable. An empirical cumulus suppression condition introduced in Emori et al. (2001) is adopted. Note here that the updraft and the downdraft of chemical species by cumulus convection are included in the model. The large-scale condensation scheme is based on Treut and Li (1991), in which subgrid probability distribution of total water mixing ratio in each grid box is assumed as a uniform distribution. Spectral coefficients are triangularly truncated at wavenumber 42 (T42), equivalent to a horizontal grid spacing of about $2.8 \circ$. The model has 32 vertical layers that are spaced at about $1-\mathrm{km}$ intervals in the free troposphere and lower stratosphere. The chemical side of the model is based on Sudo et al. (2002a, 2003), and includes a detailed online simulation of tropospheric chemistry involving the $\mathrm{O} 3-\mathrm{HO} x-$ $\mathrm{NO} x-\mathrm{CH} 4-\mathrm{CO}$ system and oxidation of NMHCs. The chemical model time step is 10 minutes. The model includes detailed dry and wet deposition schemes and heterogeneous reactions on the surface of sulfate and nitrate aerosols.

In addition to the extensive chemical reactions, forecast runs include tagged $\mathrm{CO}$ tracers. Such tracers are emitted normally over selected regions (north and south China, Japan, south Asia, northern America, Europe, and Siberia) and evolved subject to model transport schemes and normal chemical loss processes for $\mathrm{CO}$. Anthropogenic surface emissions of $\mathrm{CO}$ are taken from the Streets et al. (2003) inventory over Asia (except China), and from EDGAR (Emission Database for Global Atmospheric Research) (Olivier et al., 1996) over other regions. Surface CO emissions over China are taken from Streets et al. (private comm.,2005). The estimated annual amount emissions over China is $146 \mathrm{TgCO}$, a figure about $40 \mathrm{TgCO}$ larger than that in Streets et al. (2003). In this study, the timing of CO emission from biomass burning was estimated by using the average of the hot spot data from1995 to 2001 from Along Track Scanning Radiometer (ATSR) (Arino et al., 1999) for the daily forecast. ATSR hot spot data for 2002 were used in the post-analysis study. Tagged CO tracer is also 
considered for $\mathrm{CO}$ which is chemically produced from the oxidation of $\mathrm{CH} 4$, isoprenes, and other NMHCs.

Each daily run is fully automated and consists of two parts, a "quasi-real-time" run and forecast runs. The quasi-real-time run is derived from the NCEP final analysis (FNL) data, and steps forward one day at a time as soon as the previous day's data are available. Forecast runs use the NCEP Global Forecast System (GFS) data instead of the NCEP FNL data. The NCEP data are re-gridded from $1.0 \circ \times 1.0 \circ$ to $2.8 \circ \times 2.8 \circ$ in horizontal, and from 24 layers to 32 layers in vertical. The relaxation time for nudging the CHASER model meteorological field to the NCEP meteorological data is 1 day in the free troposphere and lower stratosphere. The relaxation time approaches 0 at the surface in this study. Sea surface temperatures (SST) are based on WMO Distributed Data Bases managed by the Japan Meteorological Agency. Winds from $10 \mathrm{hPa}$ to about $3 \mathrm{hPa}$ are calculated by using dynamical and physical procedures in the CHASER model. They are not nudged by NCEP data because the maximum height of NCEP data is lower than the top of CHASER model. Humidity is calculated using the hydrological cycle (surface source and sink, transport, convection, diffusion, condensation, and precipitation) in the CHASER model. Consequently, the temperature and humidity field do not produce destabilization or discontinuity because of inconsistencies between CHASER temperature and NCEP humidity. The forecast run is initialized from a restart file written at the end of the previous day's quasi-real-time run. Automated runs normally start at 05:00 JST (20:00 UTC of the previous day). Therefore, the 1-day forecast was available for pre-flight briefing during the PEACE campaign. Pre-formatted figures are automatically made from output from both the quasi-real-time and forecast runs. Archived output data can be used to make custom figures via the web interface (http://www.jamstec.go.jp/frcgc/gcwm).

This forecast system evolved from a prototype run with lower resolution (T21) that started in November 2000. The forecast system then switched to higher resolution (T42) with a spin-up time of 3 months for the global distribution of chemical species. Daily forecasts and archived output data have been available on a web page at the Japan Agency for Marine-Earth Science and Technology (JAMSTEC) since 1 January 2002. 


\section{Results}

The climatological and seasonal distributions of chemical species (i.e., the chemical climate) calculated by CHASER have already been evaluated in Sudo et al. (2002b, 2003). The focus here is on the validation and interpretation of the chemical structures on timescales of hours to days. The targeted features of the flights based on the chemical weather forecasts can be characterized a) pollution plumes that were affected by intercontinental transport, and $b$ ) the outflow of a polluted air mass from nearby populated regions. The global chemical weather forecast can predict anywhere where enhanced mixing ratios may occur on a day-to-day bias. However, such predictions would benefit from global or regional model forecasts with higher resolution, especially if they are used to plan flight paths.

\subsection{Meteorological Fields}

An accurate characterization of transport processes is of critical importance to flight planning and to the analysis of observations. Figure 1 compares PEACE G-II observations of meteorological parameters (wind direction, wind speed, air temperature, and relative humidity) with CHASER meteorological output. Model output was extracted along the G-II aircraft flight path and compared to aircraft observations averaged over 60 seconds. The color of each dot denotes the hight. Wind speed, and air temperature well agreed with the G-II measurements. The modeled relative humidity had a wet bias in the low-humidity regions of the figure. In addition, the model did not reproduce the supersatulated air seen in flight 12 of PEACE-A on 21 January and flight 11 of PEACE-B on 15 May. The flight paths on these dates passed through a low-pressure system, and the coarse resolution of the model failed to resolve fine structures. By same reason, the model could not capture the wind direction in the lower troposphere (red dots in Figure 1), especially in PEACE-B. The correlation coefficients between model data and observation for all G-II flights were $0.81,0.91,0.99$, and 0.66 for wind direction, wind speed, temperature, and relative humidity, respectively. The CHASER global chemical forecasting system accurately captured many of the important observed meteorological features during PEACE. The results presented here are driven by the NCEP FNL data. The forecast and hindcast meteorological fields were similar during both PEACE$\mathrm{A}$ and PEACE-B. 


\subsection{Comparison with Ground-based Observations}

The mixing ratios of chemical species calculated by the chemical weather forecasting system during PEACE were compared with values observed at three ground-based observational sites in the major sampling region of PEACE. Figure 2 shows $\mathrm{CO}$ at Minamitorishima $(24.2 \circ \mathrm{N}, 153.6 \circ \mathrm{E})$, Yonagunijima (24.3॰ N, 123.1。 E), and Ryori (39.2॰ N, 141.5॰ E). The model reproduced the observed temporal variations of each site except small peaks at Yonagunijima, especially in winter. Although biomass-burning emissions based on the 2001/2002 ATSR hot spot data were incorporated into the model, the model still underestimated $\mathrm{CO}$ mixing ratio by about $20 \mathrm{ppbv}$ at these sites in spring. The hot spot data correlated well with emission anomalies, especially for Siberia (Yurganov et al., 2005). Figure 2 also shows the regional CO tracers calculated by CHASER. Siberian CO made small contribution to the $\mathrm{CO}$ concentrations in late spring at these sites. The concentration of Siberian CO does not exceed 5 ppbv in late spring. Minamitorishima is in the southeast of Japan and is affected by maritime air and outflow from Asia. Tagged CO tracers suggest that the enhanced CO level observed at Minamitorishima on 18 January are linked to emissions from northern and southern China. The $\mathrm{CO}$ levels at Yonagunijima are strongly related to the Asian CO tracers. Some events with increased CO levels greater than $300 \mathrm{ppbv}$ occurred at Yonagunijima. Corresponding increases occurred in the China $\mathrm{CO}$ tracers in such events. Tracers of $\mathrm{CO}$ that is chemically produced from the oxidation of $\mathrm{CH} 4$, isoprenes, and other NMHCs, increased by about 5-10 ppbv in the $\mathrm{CO}$ increase event in the spring. Increases in $\mathrm{CO}$ tracers linked to chemical production from hydrocarbons in polluted air masses reflect the enhanced chemical activity in the spring.

\subsection{Convective outflow during the PEACE-B campaign}

Convective activity can play an important role in late spring, when PEACE-B was conducted. Oshima et al. (2004) evaluated the origin of air parcels sampled by the aircraft during PEACE-B from altitudes between 4 and $13 \mathrm{~km}$ using back trajectories and estimated that $69 \%$ of those air parcels that originated at or below $800 \mathrm{hPa}$ experienced convective uplifting. CCSR/NIES/FRCGC AGCM and CHASER consider tracer updraft and downdraft corresponding to deep cumulus convections. Figure 3 shows the modeled mass change of CO tracers in the free troposphere (above $2 \mathrm{~km}$ ) caused by convective transport over northern China (poleward of 30॰N) and Korea, southern China (equatorward of 30॰ N), and Japan. 
The model results show greater vertical transport resulting from deep convection over China in late spring. A clear increase also occurs in January over Japan. The increase over Japan is related to the passage of mid-latitude cyclones over Japan. The monthly budget of convective transport for May is estimated to be about $3 \mathrm{TgCO}$ over northern China, and about $3.3 \mathrm{TgCO}$ over southern China. These values are about half of all the surface emissions over China in May: The monthly budget of surface emissions in the model over northern and southern China in May is about 6.5 TgCO and 6.4 TgCO, respectively.

Several PEACE-B flights were made in May 2002 when convective CO transport was active. Figure 4 shows the vertical profiles of the observed and modeled CO mixing ratio on 14 May 2002 for flight 10 of PEACE-B. CO increased between 300-400 hPa. The model typically underestimates background $\mathrm{CO}$ level by about 20-40 ppbv compared to the PEACE-B observations, but in this flight, the model shows similar UT CO enhancement. The correlation coefficient between the observed and calculated $\Delta \mathrm{CO}$ for this flight is 0.56 in the FT. The CO concentration is observed to increase from about 120 ppbv outside the plume to around 300 ppbv in the plume. There is a similar increase in the modeled CO profile, although the modeled CO increase is smaller, from 80 to $145 \mathrm{ppbv}$, and the increase is restricted to 300 $350 \mathrm{hPa}$. Tagged CO tracers suggest that emissions from southern China are responsible for this enhanced UT plume. Emissions from southern China comprise $18-21 \%$ of the total CO mixing ratio in the plume. Emissions from northern China contribute $8-10 \%$ of the total $\mathrm{CO}$ in the plume. Figure 5 shows the sea level pressure, CO mixing ratio tendency forced by convective transport at $300 \mathrm{hPa}, \mathrm{CO}$ fluxes at $300 \mathrm{hPa}$, and modeled $\mathrm{CO}$ mixing ratio at 300 hPa calculated by CHASER. Figure 5 also show the track of flight 10 during PEACE-B on 14 May 2002. A mid-latitude cyclone was over central China on 13 May. Warm, moist southerly winds in the lower troposphere intensified ahead of this surface cyclone over southern China, converging into a front extending between $20 \circ \mathrm{N}, 100 \circ \mathrm{E}$ and $30 \circ \mathrm{N}, 115 \circ \mathrm{E}$. Deep convective clouds, with tops above $10 \mathrm{~km}$ around $30 \circ \mathrm{N}, 105 \circ-120 \circ \mathrm{E}$, are found in an infrared (IR) image obtained by the Geostationary Meteorological Satellite (GMS)-5 (See Figure 6d of Oshima et al. (2004)). CO over southern Asia in the UT was transported by southerly LT winds over southern China, and trapped by the cumulus convection in that area. The model reproduces similar convective activity around the cyclone and models the $\mathrm{CO}$ changes influenced by convective transport, as shown in Figure 5a. Convective transport changes the CO concentration at an estimated rate of 0.5-3.0 ppbv/hour at $300 \mathrm{hPa}$ over central China. The mass change of $\mathrm{CO}$ in the free troposphere caused by the uplift of cumulus 
convection was calculated by using cloud base mass flux and detraining mass flux in the model. The mass change of $\mathrm{CO}$ by the downdraft is also considered, but the effect is small compared to the uplift over central China. The convective processes associated with this cyclone began on 12 May 2002. Consequently, convection transported about $0.3 \mathrm{TgCO}$ on 12-13 May 2002, and the maximum height of the CO concentration increase caused by convective transport is between $300-400 \mathrm{hPa}$. A high $\mathrm{CO}$ region with the value of $150 \mathrm{ppbv}$ or higher can be seen over northern China and Korea in Figure 5b. The modeled CO increase by convective transport was not bee seen at $450 \mathrm{hPa}$ over central China. The model tends to underestimate the detrainment of middle convection, and it is the probable reason why the model was not able to reproduce the $\mathrm{CO}$ increase at $450 \mathrm{hPa}$ during flight 10 of PEACE-B. Five-day back trajectories for air parcels in which the highest $\mathrm{CO}$ mixing ratios were observed during flight 10 of PEACE-B indicate that these high-CO air parcels were located over central China (around 30。 N, 115。 E) 24 hours prior to the measurement (See Figure 5a and $5 \mathrm{~b}$ of Oshima et al. (2004)). The CO over central China increased from $0.98 \mathrm{Tg}$ on 11 May to $1.28 \mathrm{Tg}$ on 13 May between 300 and $400 \mathrm{hPa}$. The plume over central China was transported from the surface by the cumulus convection on 12-13 May. It was subsequently advected by westerly winds and moved over central Japan on 13-14 May.

\section{Summary and Conclusions}

Global chemical weather forecasts made with CHASER can be useful in planning flights targeting different types of synoptic scale phenomena, such as near-surface outflow from nearby polluted regions, or intercontinental plumes of pollutions in the middle and upper troposphere. The chemical forecast produced by the model was able to reproduce the $\mathrm{CO}$ values observed during the PEACE-A and PEACE-B campaign. The values were within 10$20 \%$ of the observed mixing ratios at three ground-based observational sites in the major sampling region of PEACE, and within 20-30\% of the airborne observed mean mixing ratios during PEACE. The ability to reproduce spatial and temporal variability is critical for flight planning. Although the model underestimates the background $\mathrm{CO}$ level by 20-40 ppbv compared with observations in late spring, the model can still reproduce the transport of polluted air masses in the free troposphere. The model estimated the convective transport of CO. The results suggest that about a half of the emissions over China are affected by the cumulus convection over China in late spring. 


\section{Appendix A: One-way nested global regional model based on CHASER and WRF/Chem}

We are now also developing a one-way nested global-regional air-quality forecasting (AQF) model system with full chemistry based on the CHASER (Sudo et al., 2002a) and WRF/Chem (Grell et al., 2005). Here, we shortly describe and evaluate our model system.

The global CTM part is based on the CHASER model, which is based on CCSR/NIES/FRCGC atmospheric general circulation model (AGCM) version 5.7b. The basic features of the model have been already described in Section 2. The regional CTM part is based on WRF/Chem (Grell et al. 2005). Anthropogenic emission data over Japan, except those from automobiles, are from the JCAP (Japan Clean Air Program) with $1 \mathrm{~km} \times 1 \mathrm{~km}$ resolution (Kannari et al. 2007), and anthropogenic emissions from automobiles over Japan are from EAgrid2000 (East Asian Air Pollutant Emissions Grid Inventory) with $1 \mathrm{~km} \times 1 \mathrm{~km}$ resolution (K. Murano, personal communication). Surface emissions over China and North and South Korea are taken from REAS (Regional Emission Inventory in Asia) with $0.5 \times 0.5$ resolution (Ohara et al. 2007), and surface emissions over Russia are taken from EDGAR (Emission Database for Global Atmospheric Research) with $1 \times 1$ resolution (Olivier et al. 1996). Diurnal and seasonal variations in surface emissions are taken into account in the JCAP and EAgrid2000 data, and diurnal variations are also parameterized in emissions from REAS and EDGAR following averaged variations of JCAP. Weekly variation between workdays and holidays is also taken into account in the EAgrid2000 automobile emission data. Note here that emissions based on the statistics in 2000 are applied in the present study. Biogenic emissions are based on Guenther et al. (1993). The outer domain covers Japan with 15-km horizontal resolution $(152 \times 152$ grids for chemical species $)$, and the inner domain covers the Kanto region with $5-\mathrm{km}$ resolution $(111 \times 111$ grids for chemical species). The inner and outer domains in the regional CTM have 31 vertical layers up to $100 \mathrm{hPa}$. The two-way nesting calculation is applied in the regional CTM part.

The lateral boundary of chemical species in the regional CTM is taken from the global CTM. The output of the global CTM is linearly interpolated from the Gaussian latitude and longitude grid to a Lambert conformal conic projection for use in the regional CTM. The 
lateral boundary is updated every 3 hours and linearly interpolated for each time step. We did not include feedback from the regional CTM to the global CTM; that is, the one-way nesting calculation was done between the global and regional CTMs. The system is driven by meteorological data from NCEP for the global CTM part and from the mesoscale model (MSM) of the Japan Meteorological Agency (JMA) for the regional CTM part. A 15-hour forecast has been produced four times daily at $00,06,12$, and $18 \mathrm{Z}$ with a lead time of 8-10 hours since July 2006, following a spin-up of 1 month for the global distribution of chemical species. The initial condition of the meteorological field for the regional CTM was taken from the MSM for each forecast, and the initial condition of chemical species was taken from the model output driven by the analysis meteorology.

To evaluate the model-calculated ozone, the surface ozone mixing ratio was compared to that observed at air quality monitoring stations. There are 251 stations observing surface ozone within the inner domain of the regional CTM as of August 2006. For the comparison of temporal variation, hourly averaged values of observed and modeled surface $\mathrm{O}_{3}$ mixing ratios in August 2006 are shown in Figure A-1. Observed ozone exceeded 100 ppbv from 3 to 6 August at Hanyuu in Saitama Prefecture (36 10'28'N, 139。33'21'”E, upper panel of Figure A-1), which is downwind of the Tokyo metropolitan area. The maximum value in the observation was $162 \mathrm{ppbv}$ at $16 \mathrm{Z}$ on 3 August. The model successfully reproduced the ozone maximum on 3 August. The maximum simulated value was $137 \mathrm{ppbv}$ in the model. The model also successfully captured the decrease from 3 to 7 August, but failed to show the rapid decrease on 8 August. Three typhoons (Maria, Somai, and Bopha) occurred during this period, and the difficulty of predicting the meteorological field may have led to the overestimation of ozone on 8 August. Both the model and observations indicate low levels of ozone from 14 to 17 August as typhoon 200610 (Wukong) approached Japan. The observed and modeled ozone exceeded $100 \mathrm{ppbv}$ on 11 and 13 August, and the model overestimated the ozone mixing ratio on 19 August. The modeled ozone mixing ratio was 135 ppbv, whereas the observed ozone mixing ratio was 86 ppbv. Daily variation in the ozone mixing ratio at nighttime was well reproduced by the model. The daily minimum of observed and modeled ozone exceeded 10 ppbv on 12, 15, 27, and 28 August; except for these days, the ozone level was almost zero during nighttime. The comparison between the modeled and observed daily variation in surface ozone at Kodaira in Tokyo (35.43'42”N, 139.28’38”) is shown in the lower panel of Figure A-1. Maxima of observed and modeled surface ozone at Hanyuu appeared on 3 August, and the observed and modeled ozone mixing ratios at Kodaira were 140 ppbv or higher on 5 
and 6 August. The model tended to overestimate the daytime ozone maximum especially for cloudy days, and the discrepancy of daily maximum is larger in urban area compared to that in rural area. To evaluate the model performance, a set of statistical measures provided by the U.S. Environmental Protection Agency (US EPA 1991) was evaluated for stations in the inner domain of the model. The mean normalized bias error (MNBE), the mean normalized gross error (MNGE), and the unpaired peak prediction accuracy (UPA) were 7.1\%, 9.5\%, and 9.4\%, respectively. These values are within the criteria range suggested by the U.S. EPA (MNBE< $\pm 10-15 \%$, MNGE $< \pm 30-35 \%$, and $\mathrm{UPA}< \pm 15-20 \%$ ).

\section{Acknowledgements}

We thank G. Grell, K. Sudo, and all others responsible for the development of the WRF/Chem and CHASER models. We also thank those responsible for observations at air quality monitoring stations. This study was supported by an internal special project fund of the Japan Agency for Marine-Earth Science and Technology (JAMSTEC). 


\section{References}

Arakawa, A., and W. Schubert, 1974: Interactions of cumulus cloud ensemble with the largescale environment. Part I, J. Atmos. Sci., 31, 671-701.

Arino, O., J.-M. Rosaz, and J.-M. Melinotte, 1999: World Fire Atlas with AVHRR and ATSR, paper presented at IUFRO Conference on Remote Sensing and Forest Monitoring.

Colella, P., and P. Woodward, 1984: The Piecewise Parabolic Method PPM for GasDynamic Simulations, J. Comput. Phys., 54, 174-201.

Cooper, O., et al., 2001: Trace gas signatures of the airstreams within North Atlantic cyclones: Case studies from the NARE '97 aircraft intensive, J. Geophys. Res., 106, 54375456.

Emori, S., T. Nozawa, A. Numaguti, and I. Uno, 2001: Importance of cumulus parameterization for precipitation simulation over East Asia in June, J. of Meteorol. Soc. of Japan, 79, 939-947.

Grell, G. A., S. E. Peckham, R. Schmitz, et al., 2005: Fully coupled "online" chemistry within the WRF model. Atmos. Environ., 39, 6957-6975.

Holslag, A., and B. Boville, 1993: Local versus nonlocal boundary-layer diffusion in a global climate model, J. Climate, 6, 1825-1842.

Kannari, A., Y. Tonooka, T. Bada, et al., 2007: Development of multiple-species $1 \mathrm{~km}$

$\times 1 \mathrm{~km}$ resolution hourly basis emissions inventory for Japan. Atmos. Environ., 41, 34283439, doi:10.1016/j.atmosenv.2006.12.015.

Lawrence, M., P. Rasch, R. Kuhlmann, et al., 2003: Global chemical weather forecasts for field campaign planning: predictions and observations of large-scale features during MINOS, CONTRACE, and INDOEX. Atmos. Chem. Phys., 3, 267-289.

Lee, A., G. Carver, M. Chipperfield, and J. Pyle, 1997: Three-dimensional chemical forecasting: A methodology, J. Geophys. Res., 102, 3905-3919.

Lin, S.-J., and R. Rood, 1996: Multidimensional flux-form semi-Lagrangian transport schemes, Mon. Wea. Rev., 124, 2046-2070. 
Liu, H., D. Jacob, I. Bey, R. Yantosca, and B. Duncan, 2003: Transport pathway for Asian pollution outflow over the Pacific: Interannual and seasonal variations, J. Geophys. Res., 108(D20), 8786, doi:10.1029/2002JD003102.

Mellor, G. L., and T. Yamada, 1974: A hierarchy of turbulence closure models for planetary boundary layers, J. Atmos. Sci., 31, 1791-1806.

Nakajima, T., M. Tsukamoto, Y. Tsusima, and A. Numaguti, 1995: Modeling of the radiative process in a AGCM, in Reports of a New Program for Creative Basic Research Studies,Studies of Global Environment Change to Asia and Pacific Regions, Rep. I-3, pp. 104-123, CCSR, Tokyo.

Numaguti, A.,1993: Dynamics and energy balance of the Hadley circulation and the tropical precipitation zones: Significance of the distribution of evaporation, J. Atmos. Sci., 50, 18741887.

Numaguti, A., M. Takahashi, T. Nakajima, and A. Sumi, 1995: Development of an atmospheric general circulation model, in Reports of a New Program for Creative Basic Research Studies, Studies of Global Environment Change to Asia and Pacific Regions, Rep. I-3, pp. 1-27, CCSR, Tokyo.

Numaguti, A., M. Takahashi, T. Nakajima, and A. Sumi, 1997: Development of CCSR/NIES Atmospheric General Circulation Model, no. 3 in CGER's Supercomput. Monogr. Rep., pp. 1-48, CGER, Tsukuba, Ibaraki.

Ohara, T., H. Akimoto, J. Kurokawa, et al., 2007: Asian emission inventory for anthropogenic emission sources during the period 1980-2020. Atmos. Chem. Phys. Dis., 7, 6843-6902, doi:www.atmos-chem-phys-discuss.net/7/6843/2007/.

Olivier, J. G. J., A. F. Bouwman, C. W. M. Van der Maas, et al., 1996: Description of EDGAR Version 2.0. A set of global emission inventories of greenhouse gases and ozonedepleting substances for all anthropogenic and most natural sources on a per country basis and on $1 \bullet \times 1$ grid. RIVM/TNO rep., RIVM, Bilthoven, number nr. 711060 002, 1006 .

Oshima, N., et al., 2004: Asian chemical outflow to the Pacific in late spring observed during the PEACE-B aircraft mission, J. Geophys. Res., 109, D23S05, doi:10.1029/2004JD004976.

Pan, D.-M., and D. Randall, 1998: A cumulus parameterization with a prognostic closure, $Q$. J. R. Meteorol. Soc., 124, 949-981. 
Streets, D., et al., 2003: An inventory of gaseous and primary aerosol in Asia in the year 2000, J. Geophys. Res., 108(D21), 8809, doi:10.1029/2002JD003093.

Sudo, K., M. T. J. ichi Kurokawa, and H. Akimoto, 2002a: CHASER: A global chemical model of the troposphere 1. Model description, J. Geophys. Res., 107(D21), 4339, doi: 10.1029/2001JD001113.

Sudo, K., M. Takahashi, and H. Akimoto, 2002b, CHASER: A global chemical model of the troposphere 2. Model results and evaluation, J. Geophys. Res., 107(D21), 4586, doi: 10.1029/2001JD001114.

Takigawa, M., K. Sudo, H. Akimoto, et al., 2005: Estimation of the contribution of intercontinental transport during PEACE campaign by using a global model. J. Geophys. Res., 110, doi:10.1029/2005JD006226.

Treut, H. L., and Z.-X. Li, 1991: Sensitivity of an atmospheric general circulation model to prescribed SST changes: feedback effects associated with the simulation of cloud optical properties, Climate Dynamics, 5, 175-187.

Uno, I., G. Carmichael, D. Streets, et al., 2003: Regional chemical weather forecasting system CFORS: Model descriptions and analysis of surface observations at Japanese island stations during the ACE-Asia experiment. J. Geophys. Res., 108, doi:10.1029/2002JD002845.

US EPA, 1991: Guideline for regulatory application of the urban airshead model. Number EPA-450/4-91-013 in US EPA Report, Office of Air and Radiation, Office of Air Quality Planning and Standards, Technical Support Division, Research Triangle Park, North Carolina, US.

Yurganov, L., et al., 2005: Increased Northern Hemispheric carbon monoxide burden in the troposphere in 2002 and 2003 detected from the ground and from space, Atmos. Chem. Phys., $5,563-573$. 
a) Wind direction for all G-II flights during PEACE pampaign

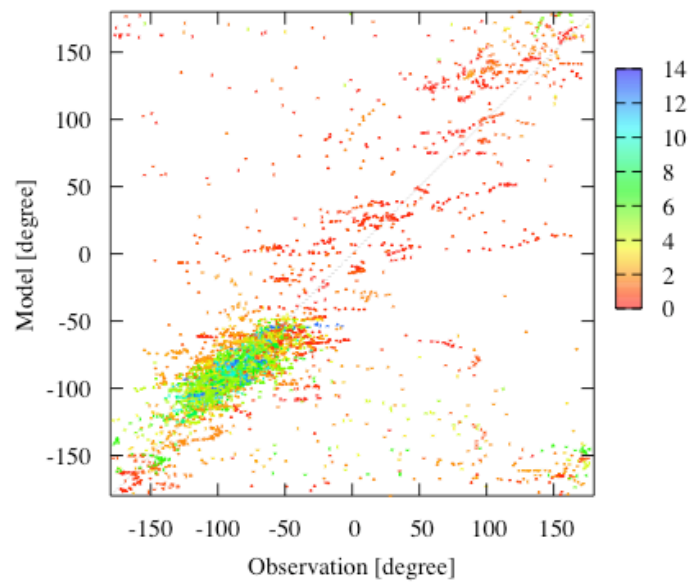

c) Temperature for all G-II flights during PEACE pampaign

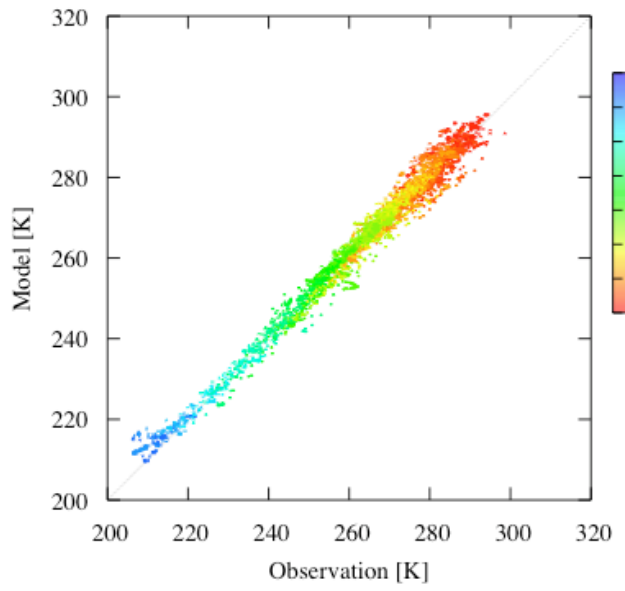

b) Wind speed for all G-II flights during PEACE pampaign

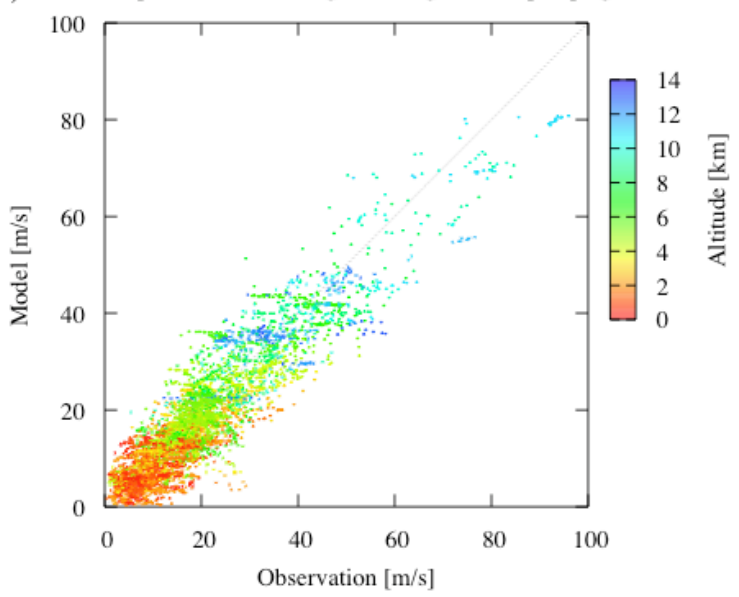

d) Relative Humidity for all G-II flights during PEACE pampaign

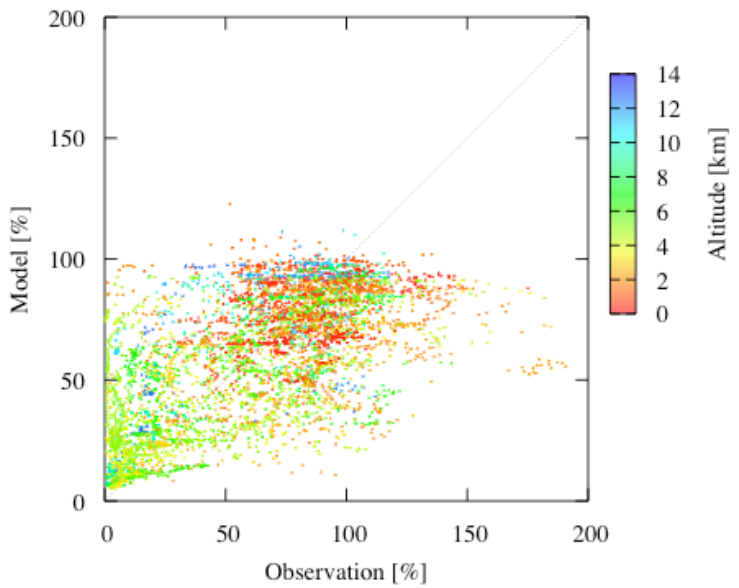

Figure 1. Comparison between PEACE G-II airborne meteorological parameters and global chemical weather forecasting system output fields along the flight paths. Colors denote altitudes. Dots and crosses denote PEACE-A and PEACE-B data, respectively. 
a)
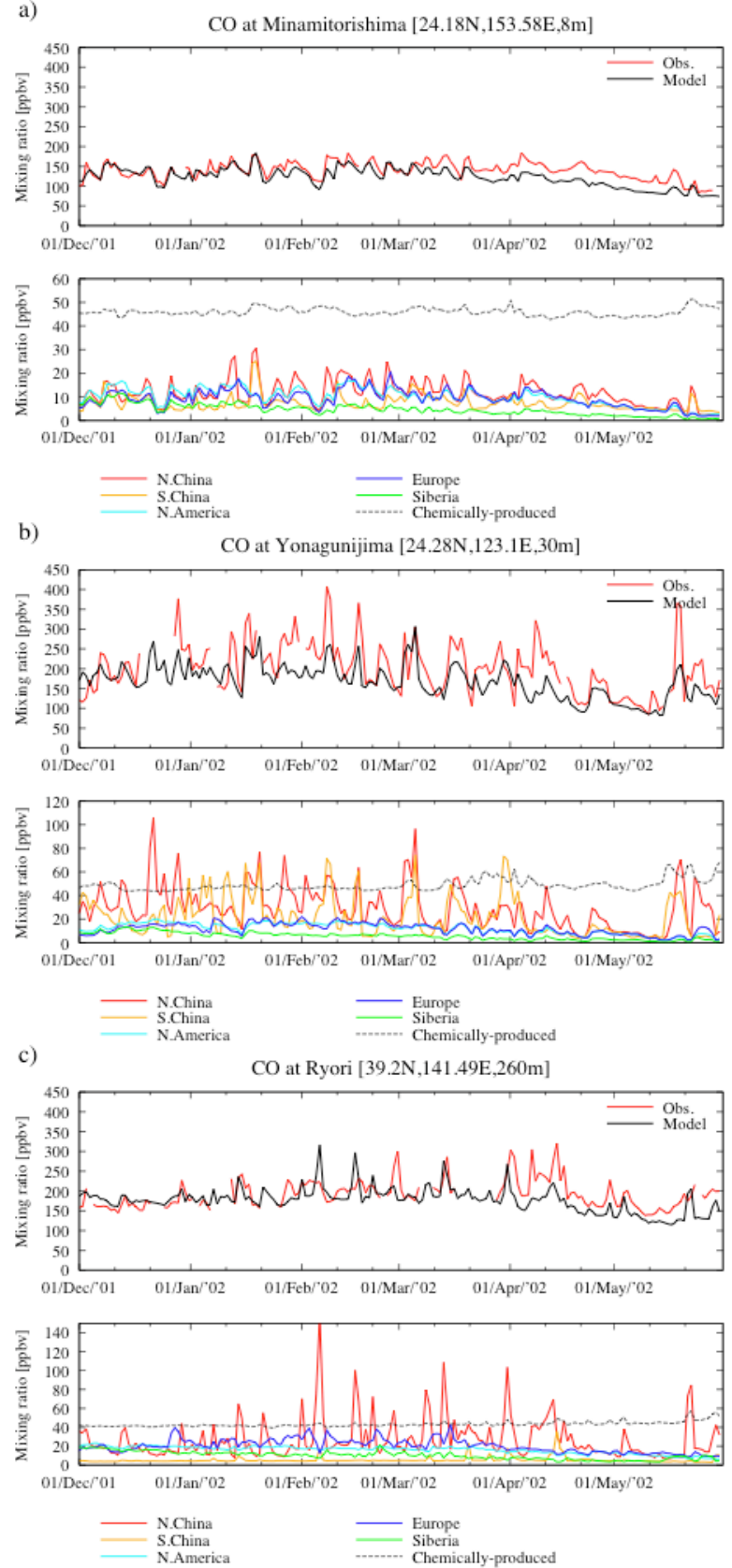

Figure 2. Observed (red lines) and modeled (black lines) surface $\mathrm{CO}$ mixing ratio at a) Minamitorishima $(24.2 \circ \mathrm{N}, 153.6 \circ \mathrm{E})$, b) Yonagunijima $(24.3 \circ \mathrm{N}, 123.1 \circ \mathrm{E})$, and c) Ryori $(39.2 \circ \mathrm{N}$, 141.5॰E). Regional tagged CO tracers for northern China and Korea (red), southern China (orange), south Asia (gray), Europe (blue), North America (cyan), and chemically production (dotted lines) are also shown. 


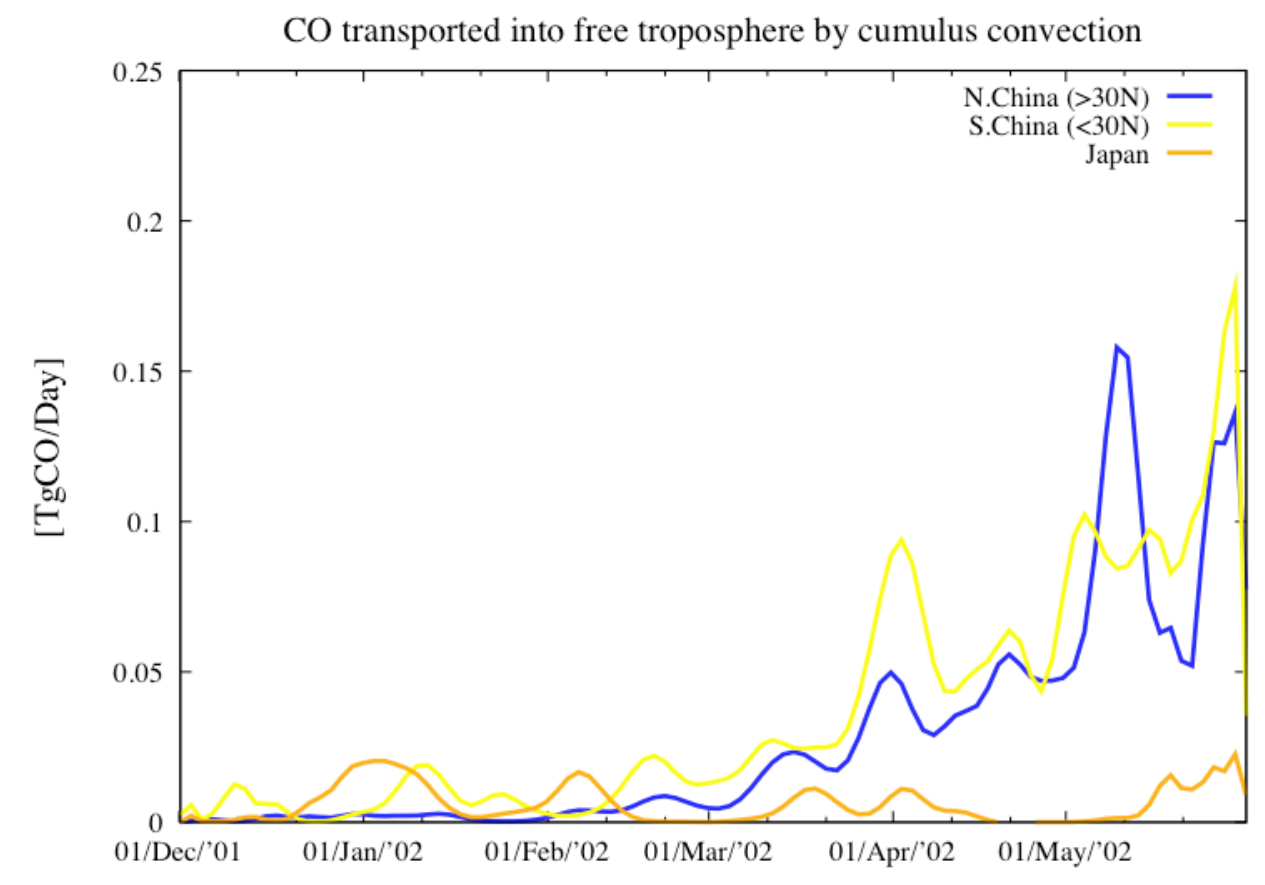

Figure 3. Ten-day running mean of CO transport by convection over northern China (blue line), southern China (yellow line), and Japan (orange line) during PEACE as calculated by CHASER. The units are TgCO. 
a) CO (PEACE-B Flight\#10 14/May/2002)

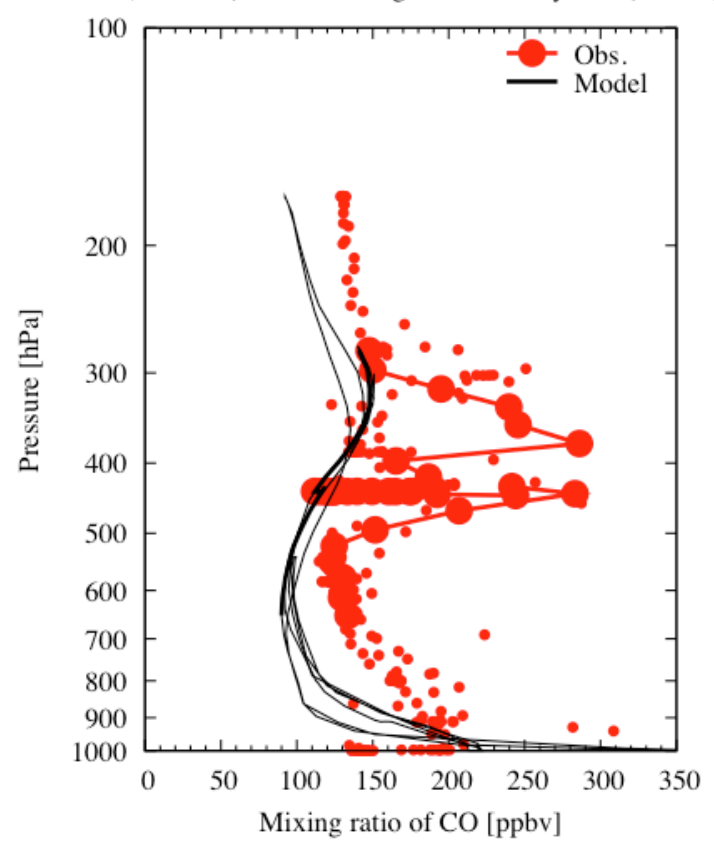

b) Tagged CO for PEACE-B Flight\#10

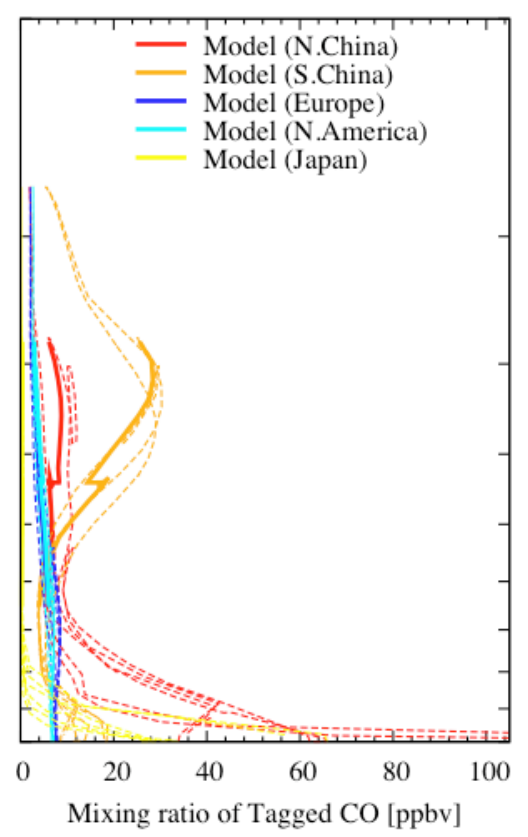

Figure 4. a) Vertical profiles of the observed $\mathrm{CO}$ mixing ratios (red circles), along with the model output corresponding to the flight tracks for PEACE-B flight 10 on 14 May 2002. Black line denotes the total CO calculated by CHASER. B) Regional tagged CO tracers for northern China and Korea (red), southern China (orange), Europe (blue), North America (cyan), Siberia (green), Japan (yellow), and biomass-burning outside from Asia (gray). The bold lines indicate CO values from 6:48 UTC to 7:22 UTC, respectively. 
CHASER CO at 18UT 13 MAY 2002

a) SLP/CO transport by convection [ppbv/hour]

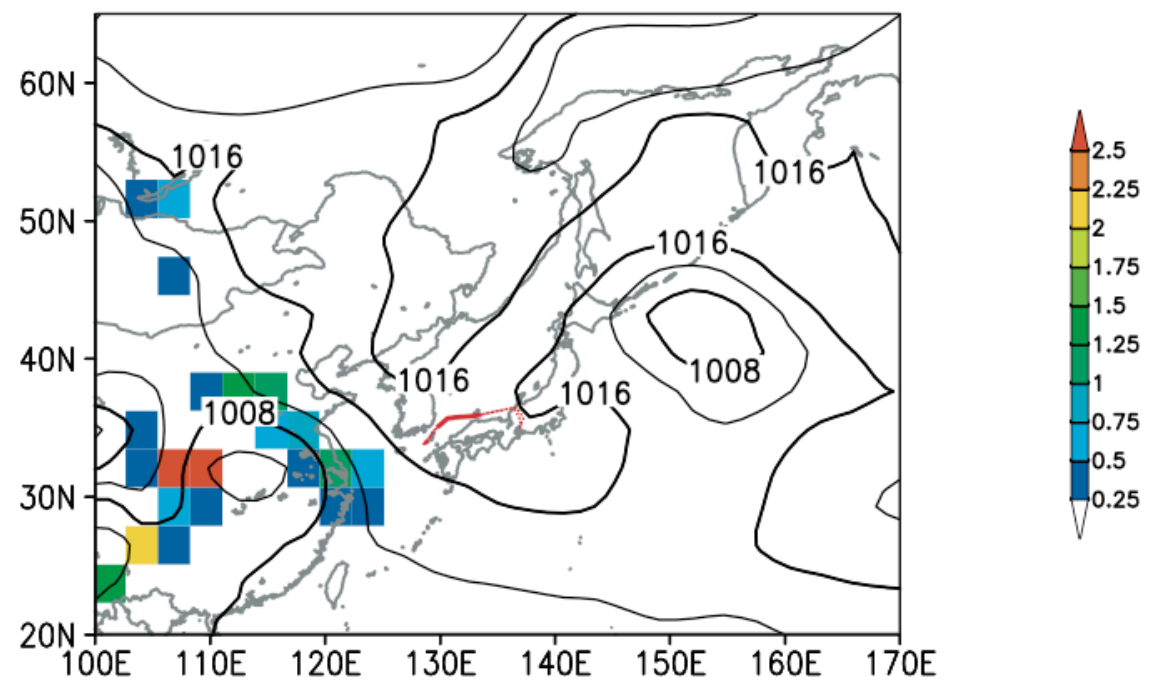

b) $\quad \mathrm{CO}$ mixing ratio / CO flux at $300 \mathrm{~Pa}$

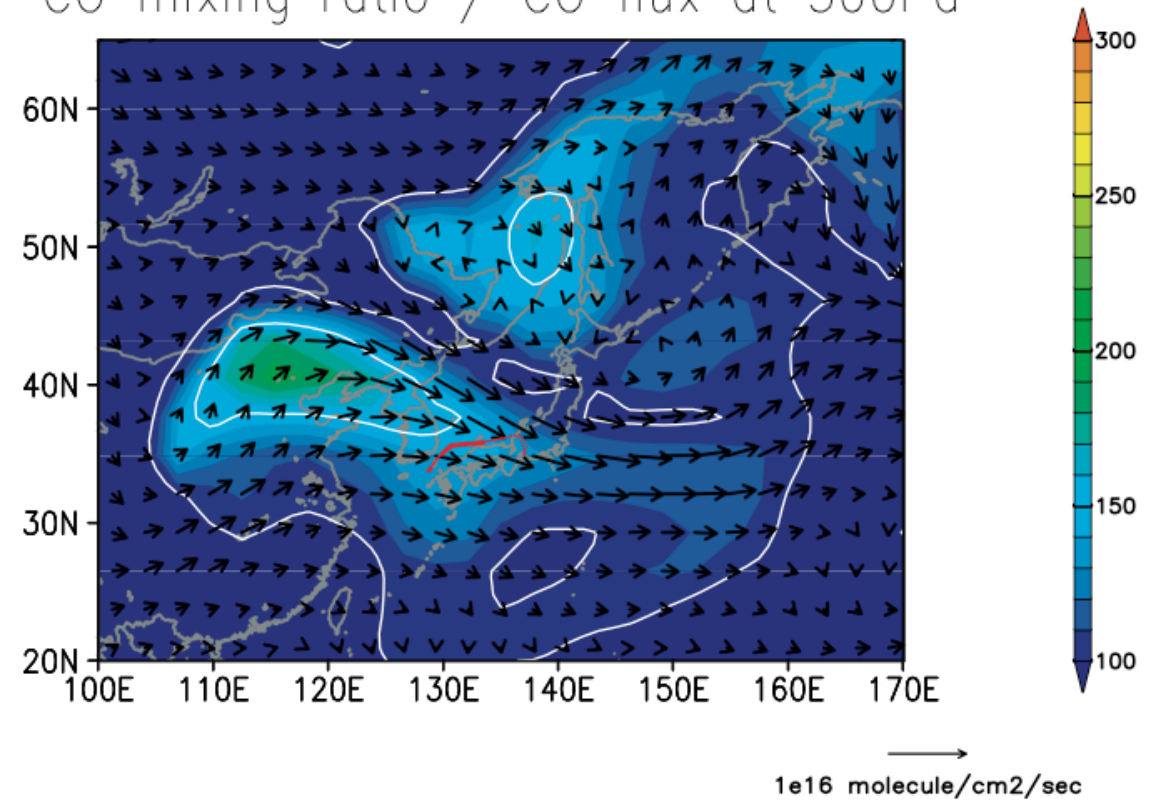

Figure 5. a) Sea level pressure (contours, units of $\mathrm{hPa}$ ), and $\mathrm{CO}$ tendency by convective transport at $300 \mathrm{hPa}$ at 18:00 UTC on 13 May 2002 (color tones, units of ppbv/hour), b) CO mixing ratio and horizontal $\mathrm{CO}$ flux at $300 \mathrm{hPa}$ at 18:00 UTC on 13 May 2002. The contour interval is $50 \mathrm{ppbv}$. The unit length is shown below the figure. Red lines denotes the track of flight 10 of PEACE-B on 14 May 2002, and the leg from 6:48 UTC to 7:22 UTC is shown with the bold line. 

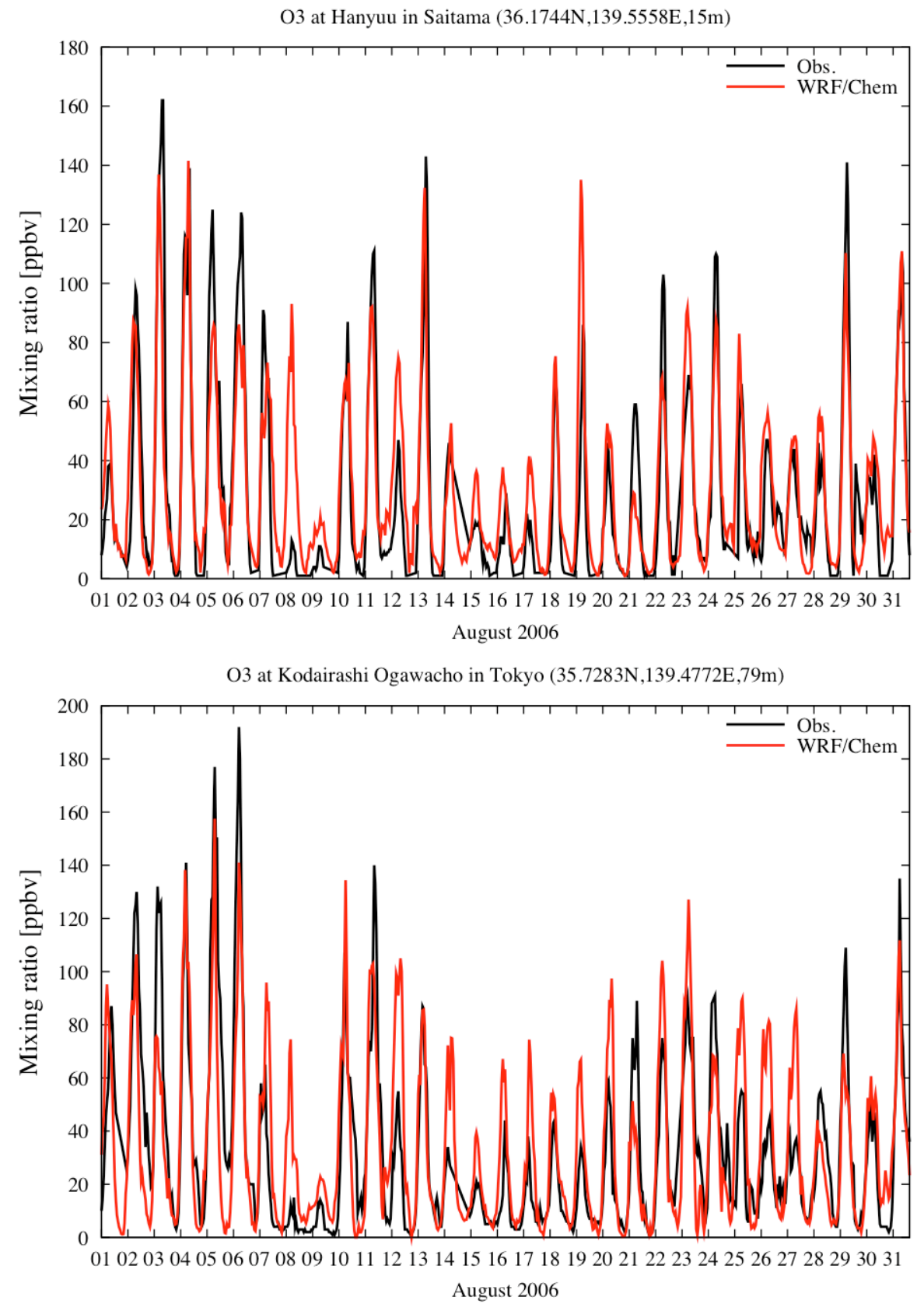

Figure A-1: Hourly observed (black) and modelled (red) surface ozone mixing ratio in August 2006 at Hanyuu in Saitama prefecture (upper panel) and Kodaira in Tokyo (lower panel). 